\title{
Utility of total lymphocyte count as a surrogate for absolute CD4 count in the adult Indian HIV population: A prospective study
}

Suman S. Karanth, N. R. Rau, Anurag Gupta ${ }^{1}$, Asha Kamath², Vikram Shanbhogue, Pruthvi B. C. ${ }^{3}$

Departments of Medicine, and ${ }^{2}$ Community Medicine, Kasturba Medical College, Manipal, 'Department of Neurosurgery, Adarsha Superspeciality Hospital, Udupi, ${ }^{3}$ Department of Medicine, Vaalsalya Hospital, Shimoga, Karnataka, India

\begin{tabular}{|c|}
\hline Access this article online \\
\hline Website: www.avicennajmed.com \\
\hline DOI: 10.4103/2231-0770.127413 \\
\hline Quick Response Code: \\
$\square$ \\
\hline
\end{tabular}

\begin{abstract}
Background: Standard methods of CD4 counts and plasma viral load estimation require specialized equipment, highly trained personnel and are extremely expensive. This remains a major challenge for the initiation of anti-retroviral therapy for patients in resource-limited settings. Objective: To assess the clinical utility of the total lymphocyte count (TLC) to serve as a surrogate marker for predicting a CD4 counts $<350 \mathrm{cell} / \mathrm{mm}^{3}$ in patients with HIV. Materials and Methods: A prospective study of 200 consecutive newly detected highly active anti-retroviral therapy (HAART) naïve HIV patients admitted over a one year period was conducted. Linear regression, Pearson correlation and receiver operating characteristic $(\mathrm{ROC})$ curves were used to calculate the relationship between TLC and CD4 counts. Results: A significant correlation between TLC and CD4 count was observed $(r=0.682, P<0.001)$. TLC cut off of $1200 \mathrm{cell} / \mathrm{mm}^{3}$ as a predictor of $C D 4$ count $<350$ cell $/ \mathrm{mm}^{3}$ had $73.1 \%$ sensitivity, $100 \%$ specificity, $100 \%$ positive predictive value (PPV) and $51.4 \%$ negative predictive value (NPV). Raising the cutoff to $1500 \mathrm{cells} / \mathrm{mm}^{3} \mathrm{improved}$ the sensitivity to $82.1 \%$ with $88.2 \%$ specificity, $96.5 \%$ PPV, $44.4 \%$ NPV. The ROC curve demonstrated highest area under curve $(A \cup C=0.8)$ for TLC of $1500 \mathrm{cell} / \mathrm{mm}^{3}$. Conclusion: The study showed that TLC cutoff value of $1500 \mathrm{cells} / \mathrm{mm}^{3}$ was a cost effective surrogate marker for CD4 counts $<350$ cells $/ \mathrm{mm}^{3}$ in resource-limited settings.
\end{abstract}

Key words: CD4 count, human immunodeficiency virus, surrogate marker, total lymphocyte count

\section{INTRODUCTION}

The burden of HIV remains high for patients and their families especially in resource-limited settings. It is estimated that 40 million people with human immunodeficiency virus (HIV) reside in resource-limited settings. Among them it is reported that 6 million require highly active anti retroviral therapy (HAART). ${ }^{[1]}$ In India alone, there are 2-3 million people infected with HIV. ${ }^{[2]}$ Ideally the WHO recommends regular combined immunological and virological monitoring for all HIV-infected patients. ${ }^{[3]}$ Analysis for viral loads and CD4 counts require not only sophisticated equipment, but in addition, highly skilled laboratory personnel, ${ }^{[4]}$ the overall cost being reported to be more than $\$ 1,000$ per person per year. ${ }^{[5]}$ This produces a colossal financial burden especially in a country like India. As a consequence, there are irregular follow-ups, delay in therapy, increased disease burden and a resultant alarming multi-drug resistance. To overcome these problems, in April 2002 WHO recommended the usage of total lymphocyte count (TLC) less than 1000 to 1200 cells $/ \mathrm{mm}^{3}$ as indication to start HAART in resource-limited settings. ${ }^{[6]}$ There are however conflicting reports as to whether TLC is a reliable substitution for CD4 count. In 2013, WHO revised its guidelines and recommended therapy to patients with severe or advanced HIV clinical disease (WHO clinical stage 3 
or 4) with a CD4 count $\leq 350$ cells $/ \mathrm{mm}^{3}$ regardless of the clinical stage in patients with CD 4 count $>350$ cells $/ \mathrm{mm}^{3}$ and $\leq 500 \mathrm{cell} / \mathrm{mm}^{3}{ }^{\left[{ }^{[7]}\right.}$ WHO also recommends the serial CD4 measurements to be more informative than individual value. This potentially raises a number of issues regarding affordability, availability and the technical expertise to perform the test.

In view of the high costs and limited availability of resources to estimate absolute CD4 counts, a study was initiated to assess the adequacy of using TLC as a suitable replacement for CD4 counts. In addition, we also studied the various values of TLC in an attempt to find the cutoff with the maximum sensitivity and specificity to predict a CD $4<350$ cells $/ \mathrm{mm}^{3}$. The effect of addition of hemoglobin to the TLC cutoff was also studied.

\section{MATERIALS AND METHODS}

\section{Patients}

This study was conducted in Kasturba Hospital, Manipal, Karnataka, which is a 2500 bedded tertiary care centre. Two hundred consenting HIV positive patients were recruited over a one year period. The patients were recruited consecutively from our Integrated Counselling and Testing Center (ICTC). All HIV positive cases at all stages of illness, above 18 yrs were included. Patients on HAART therapy, pregnant women, and pediatric age group were excluded. No other medications were being received by the patient. Patients with opportunistic infections or any inter-current infection likely to alter the lab parameters were excluded. Ethical approval was obtained from the institutional ethical board.

Blood of $5 \mathrm{ml}$ was collected in a vacutainer with ethylenediaminetetraacetic acid (EDTA) using the standard precautions. Samples were collected between 9 am to 12 noon to prevent circadian variation and were analyzed simultaneously. Serum hemoglobin, total leucocyte count, and differential counts were obtained. CD4 counts were estimated using flow cytometry techniques. Total leukocyte count was measured using flow cytometry (EPICS $\times \mathrm{L}$, Beckman-Coulter, Fullerton, California, USA). Using the total and differential leucocyte counts, total lymphocyte count (TLC) was calculated.

\section{Statistical analysis}

Percentages were used to describe categorical variables. Continuous variables were described using median and interquartile range. Statistical Package for the Social Sciences software (SPSS statistics version 17, Chicago IL, USA) was used to analyze the data. Both linear and logistic regressions were performed to determine whether TLC was a predictor of $\mathrm{CD} 4$ count. For the logistic regression analysis $\mathrm{CD} 4$ count was analyzed as a categorical variable $\left(<350\right.$ cells $/ \mathrm{mm}^{3}$ and $>350$ cells $/ \mathrm{mm}^{3}$ ). Step-wise multiple regression with hemoglobin as an independent predictor of CD4 count was also performed. Pearson correlation coefficient was determined for age, hemoglobin, total leucocyte count and TLC against CD4 count.

Receiver operating characteristics (ROC) was used to determine the cut off for TLC representing the best sensitivity, specificity, positive predictive value (PPV) and negative predictive value (NPV) to predict CD4 count $<350$ cells $/ \mathrm{mm}^{3}$. Cutoffs ranging between 1200 to 1800 cells $/ \mathrm{mm}^{3}$ were calibrated and the area under the curve (AUC) was used to compare the sensitivity and specificity of each category.

\section{RESULTS}

A total of $200 \mathrm{HIV}$ positive individuals were included with a mean age of $39.5 \pm 9$ yrs. Out of the total, 162 $(81 \%)$ of the patients recruited were males. CD4 counts $<350$ cell $/ \mathrm{mm}^{3}$ were seen in $80 \%$ of the subjects. The median CD4 count was 165.2 cells $/ \mathrm{mm}^{3}$ \{ Interquantile range $\mathrm{IQR}=(87,260)\} ;$ Median total leucocyte count was 5700 cells $/ \mathrm{mm}^{3}\{\mathrm{IQR}=(3600,7300)\}$; Median total lymphocyte count was 1138 cells $/ \mathrm{mm}^{3}\{\mathrm{IQR}=(726,1857)\}$ as depicted in Table 1. Table 2 shows correlation coefficient $r$ between CD4 cell count and parameters TLC $(r=0.682$, $P<0.001)$ and hemoglobin $(\mathrm{r}=0.369, P<0.001)$ to be significant. However, correlations with age $(\mathrm{r}=-0.157$, $P<0.154)$ and total leucocyte count $(\mathrm{r}=0.166, P<0.146)$ were not statistically significant.

Table 3 depicts the sensitivity, specificity, NPV and PPV of various TLC cutoff values to predict a CD4 count $<350$ cells $/ \mathrm{mm}^{3}$. TLC cutoff values from 1200 to 1800 cells $/ \mathrm{mm}^{3}$ were compared to search for the value with highest sensitivity and specificity. With a cut off of 1200 , the sensitivity was lower (73\%) with a specificity of $100 \%$, PPV of $100 \%$ and NPV of $51.4 \%$. However, with a TLC of 1500 cells $/ \mathrm{mm}^{3}$ the sensitivity was higher (82.1\%) with $88.2 \%$ specificity, a $96.5 \% \mathrm{PPV}$ and $44.4 \% \mathrm{NPV}$. Thus a TLC cutoff value of 1500 cells $/ \mathrm{mm}^{3}$ best predicted CD 4 count $<350$ cells $/ \mathrm{mm}^{3}$. The ROC curve for TLC of 1500 as a predictor for CD 4350 cells $/ \mathrm{mm}^{3}$ showed the highest AUC of 0.8 [Figure 1] as compared to the other cutoff values for TLC. The addition of hemoglobin to TLC of 1500 cells $/ \mathrm{mm}^{3}$ did not increase either the sensitivity or specificity for predicting CD $4<350$ cells $/ \mathrm{mm}$. 


\begin{tabular}{|c|c|c|}
\hline Parameter (cells $/ \mathrm{mm}^{3}$ ) & Median & IQR \\
\hline CD4 count & 165.2 & $(87,260)$ \\
\hline Total leucocyte count & 5700 & $(3600,7300)$ \\
\hline TLC & 1138 & $(726,1857)$ \\
\hline
\end{tabular}

\begin{tabular}{lcc}
\hline Table 2: Correlation of CD4 count with other parameters \\
\hline Parameter & $\boldsymbol{r}$ & $\boldsymbol{P}$ \\
\hline Age (year) & -0.157 & $0.154(\mathrm{NS})$ \\
Hb $(\mathrm{g} / \mathrm{dl})$ & 0.369 & $<0.00 \mathrm{I}(\mathrm{S})$ \\
WBC count $\left(\right.$ cells $\left./ \mathrm{mm}^{3}\right)$ & 0.166 & $0.146(\mathrm{NS})$ \\
TLC (cells $\left./ \mathrm{mm}^{3}\right)$ & 0.682 & $<0.00 I(\mathrm{~S})$ \\
\hline TLC: Total lymphocyte count,WBC:White blod cell count, Hb: Hemoglobin, \\
r: Correlation coefficient, NS: Not significant $(P>0.05)$, S: Significant
\end{tabular}

\begin{tabular}{|c|c|c|c|c|}
\hline $\begin{array}{l}\text { TLC optimal cut } \\
\left.\text { off (cells } / \mathrm{mm}^{3}\right)\end{array}$ & $\begin{array}{l}\text { Sensitivity } \\
\text { (\%) }\end{array}$ & $\begin{array}{l}\text { Specificity } \\
(\%)\end{array}$ & $\begin{array}{l}\text { PPV } \\
\text { (\%) }\end{array}$ & $\begin{array}{l}\text { NPV } \\
\text { (\%) }\end{array}$ \\
\hline 1200 & 73 & 100 & 100 & 51.4 \\
\hline 1300 & 73 & 94.2 & 98 & 47.1 \\
\hline 1400 & 79 & 98 & 94 & 53.3 \\
\hline 1500 & 83.1 & 88.2 & 96.5 & 44.4 \\
\hline 1600 & 82 & 82.4 & 94.8 & 53.8 \\
\hline 1700 & 85 & 76.5 & 93.4 & 56.5 \\
\hline 1800 & 85 & 70.6 & 91.9 & 54.5 \\
\hline
\end{tabular}

TLC: Total lymphocyte count, PPV: Positive predictive value, NPV: Negative predictive value, Note: Data are given as numbers.

\section{DISCUSSION}

In a resource-constrained setting like India with 2.4 million HIV-infected individuals, it becomes imperative to look for alternative diagnostic techniques, as the cost for CD4 count and plasma viral load is $\$ 25$ and $\$ 100$, respectively. ${ }^{[5]}$ This prohibits not only the timely initiation of HAART, but the serial monitoring of progression of disease and risk for opportunistic infection. As TLC is calculated from a much cheaper complete blood picture, it proves to be cost-effective in areas where the sophisticated and labour intensive flow-cytometry techniques for CD4 count are unavailable.

There have many conflicting reports regarding whether TLC is a suitable substitute for CD4 count with a quest for a better predictor. A study performed by Akinola et al., ${ }^{[8]}$ in Nigeria using a WHO recommended cutoff for TLC $<1200$ cells $/ \mathrm{mm}^{3}$ did not find it to bea significant predictor for CD $4<200$ cells $/ \mathrm{mm}^{3}$. With TLC $<1200$ cells $/ \mathrm{mm}^{3}, 1$ in 3 patients were deprived of the required treatment. However, study by Myamburi et al., reported the effectiveness of TLC as an inexpensive tool to monitor the progress of patients on HAART therapy. ${ }^{[9]}$ Studies by Spacek et al.,

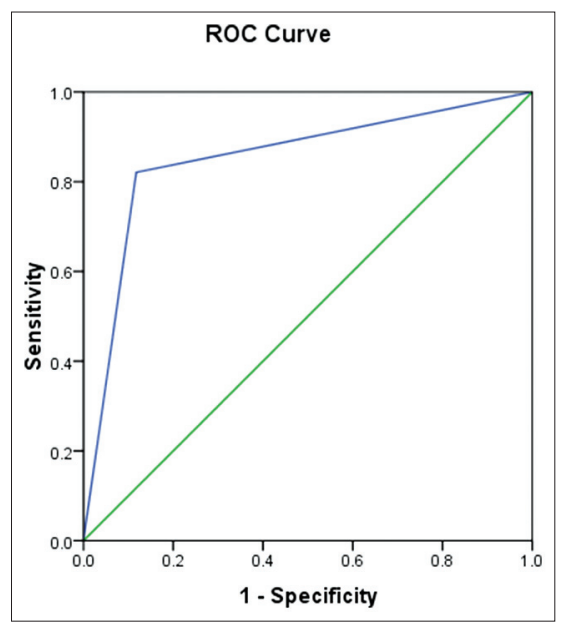

Figure 1: ROC curve with sensitivity and 1-specificity of TLC cutoff of 1500 cells $/ \mathrm{mm}^{3}$ identifying a CD4 count of $<350 \mathrm{cells} / \mathrm{mm}^{3}(\mathrm{AUC}=0.8)$

and Lee et al., showed that the WHO recommended TLC $<1200$ cells $/ \mathrm{mm}^{3}$ with hemoglobin $<12 \mathrm{gm} / \mathrm{dL}$ was in fact an effective predictor for CD $4<200$ cells $/ \mathrm{mm}^{3}$. ${ }^{[1,10,11,12]}$

In our study, median levels for CD4 count and TLC were lower than similar studies conducted by Akanmu et al., and Akinola et al., ${ }^{[8,13]}$ [Table 1]. The correlation coefficient between CD4 count and TLC $(r=0.682, P<0.001)$ showed a significant positive correlation while correlation with age $(\mathrm{r}=-0.157, P<0.154)$ and total leucocyte count $(\mathrm{r}=0.166$, $P<0.146)$ was poor. Similar results were obtained in other studies. ${ }^{[7,13]}$ We also found a strong correlation between CD4 count and hemoglobin $(\mathrm{r}=0.369, P<0.001)$, also seen in studies done by Spacek and his colleagues. ${ }^{[10]}$

Various studies indicate different TLC cutoff to predict a CD4 $<200$ cells $/ \mathrm{mm}^{3}$. In our study, in contrast to studies done by Spacek et al., Lee et al., and Badri et al., ${ }^{[10,11,14]}$ failed to demonstrate a strong sensitivity between the WHO recommended TLC $<1200$ cells $/ \mathrm{mm}^{3}$ and CD4 count $<200$ cells $/ \mathrm{mm}^{3}$. As CD4 count $<350$ cells $/ \mathrm{mm}^{3}$ is used as a cut off for anti-retroviral therapy, we further evaluated for a correlation between TLC and CD4 count $<350 \mathrm{cell} / \mathrm{mm}^{3}$. With a TLC cutoff of 1200 cells $/ \mathrm{mm}^{3}$, while the specificity approached $100 \%$, the sensitivity was a mere $73 \%$ [Table 3]. With TLC $<1200$ cells $/ \mathrm{mm}^{3}$ taken as the cutoff, there existed a high chance of patients being misdiagnosed and not receiving therapy. An increased cut off for TLC improved the sensitivity with marginal lowering of specificity. With a TLC cutoff of 1500 cells $/ \mathrm{mm}^{3}$, the sensitivity improved to $83.1 \%$ with a specificity of $88.2 \%$, PPV of $96.5 \%$ and NPV of $44.4 \%$. As compared to the remaining TLC cutoff shown in Table 3, cut off of 1500 also yielded the best sensitivity and specificity. With this cut-off, $83 \%$ of the patients with CD4 count $<350$ cells $/ \mathrm{mm}^{3}$ were identified. More individuals 
requiring therapy were identified with this raised cutoff value. The ROC curve was plotted with TLC cut off of 1500 cells $/ \mathrm{mm}^{3}$ and area under the curve was 0.8 , which was more significant than the remaining cutoffs used. Similar higher TLC cutoff values have been used in studies by Jacobson et al., ${ }^{[15]}$ where he used a TLC $<1900$ cells $/ \mathrm{mm}^{3}$ as cutoff to predict CD4 count $<350$ cells $/ \mathrm{mm}^{3}$. Kumaraswamy and his colleagues ${ }^{[16]}$ observed that with a TLC, $<1400$ cells $/ \mathrm{mm}^{3}, 73 \%$ of patients with CD4 cell counts $<200$ cells $/ \mathrm{mm}^{3}$ (sensitivity: $73 \%$, specificity: $88 \%$, PPV: $76 \%$, NPV: $86 \%$ ) were identified. With a TLC $<1700$ cells $/ \mathrm{mm}^{3}, 70 \%$ of patients with a CD4 cell count of $<350$ cells $/ \mathrm{mm}^{3}$, requiring initiation of therapy for opportunistic infection, were identified. In contrast, some studies have shown TLC to be an imperfect predictor of CD4 count. ${ }^{[7,17]}$ Nonetheless, the authors have recommended TLC be used in areas with limited access to CD4 count until a cheaper alternative is found. We did not find a statistically significant correlation for TLC as a predictor for CD4 $<500$ cells $/ \mathrm{mm}^{3}$. We hypothesized this to be due to majority of our patients having a CD 4 count $<350$ cells $/ \mathrm{mm}^{3}$. Our study helps to identify majority of patients with a CD4 count $<350$ cells $/ \mathrm{mm}^{3}$ who require anti-retroviral therapy as per current WHO guidelines using a TLC cutoff of 1500 cell $/ \mathrm{mm}^{3}$. Larger studies with patients with a wider range of $\mathrm{CD} 4$ counts are required. The utility of TLC as a predictor for $\mathrm{CD} 4$ count still holds good in resource-limited settings.

\section{CONCLUSION}

We conclude that TLC is a useful and suitable surrogate for predicting CD4 count $<350$ cells $/ \mathrm{mm}^{3}$. However, as opposed to the WHO cut off for TLC, we recommend TLC $<1500$ cells $/ \mathrm{mm}^{3}$. With TLC $<1500$ cells $/ \mathrm{mm}^{3}$ more number of individuals requiring anti-retroviral therapy were identified. Though hemoglobin levels correlated with CD4 count, its addition to TLC did not provide surplus information. Other hematological parameters were not useful predictors of CD4 count. Larger study population along with independent studies for pregnant women are required which were the limitations in our study.

\section{Authors contributions}

SSK and AG conceived the study, carried out the study and drafted the manuscript. VS and PC helped in its coordination. AK performed the statistical analysis of the data. SSK and AG are the guarantors of the paper. All authors read and approved the final manuscript.

\section{Ethical approval}

Ethical approval was obtained from Kasturba Hospital, Manipal University-Institutional Ethical Review board.

\section{REFERENCES}

1. World Health Organization. Scaling up antiretroviral therapy in resource-limited Settings: Treatment guidelines for a public health approach. 2003 revision. Geneva, World Health Organization, 2003,

2. UNAIDS. UNAIDS/WHO AIDS epidemic update, 2007.

3. World Health Organization. Antiretroviral therapy for HIV infection in adults and adolescents: Recommendations for a public health approach, 2006.

4. Crowe S, Turnbull S, Oelrichs R, Dunne A. Monitoring of human immunodeficiency virus infection in resource-constrained countries. Clin Infect Dis 2003;37 Suppl 1:S25-S35.

5. National Institutes of Health. Guidelines for the Use of Antiretroviral Agents in HIV-1-Infected Adults and Adolescents, 2006.

6. WHO approved draft treatment guidelines for HIV-infected people in resource limited settings. In: The Hopkin's HIV report. The John Hopkins University AIDS Service 2002;14:1-4.

7. World Health Organization. Consolidated guidelines on the use of antiretroviral drugs for treating and preventing HIV infection, 2013 revision.

8. Akinola NO, Olasode O, Adediran IA, Onayemi O, Murainah A, Irinoye $\mathrm{O}$, et al. The search for a predictor of $\mathrm{CD} 4$ cell count continues: Total lymphocyte count is not a substitute for CD4 cell count in the management of HIV-infected individuals in a resource-limited setting. Clin Infect Dis 2004;39:579-81.

9. Mwamburi DM, Ghosh M, Fauntleroy J, Gorbach SL, Wanke CA. Predicting CD4 count using total lymphocyte count: A sustainable tool for clinical decisions during haart use. Am J Trop Med Hyg 2005;73:58-62.

10. Spacek LA, Griswold M, Quinn TC, Moore RD. Total lymphocyte count and hemoglobin combined in an algorithm to initiate the use of highly active antiretroviral therapy in resource-limited settings. AIDS 2003;17:1311-7.

11. Lee SS, Wong KH. The use of total lymphocyte count (TLC) as an independent criterion for initiating HAART in resource-poor countries. J Infect 2005;50:66-7.

12. Seyed MA, Fatemeh A, Majid F. Correlation between total lymphocyte count, hemoglobin, hematocrit and CD4 count in HIV/AIDS patients. Acta Medica Iranica 2009;47:1-4.

13. Akanmu AS, Akinsete I, Eshofonie AO, Davies AO, Okanny CC. Absolute lymphocyte count as surrogate for CD4+ cell count in monitoring response to antiretroviral therapy. Niger Postgrad Med J 2001;8:105-11.

14. Badri M, Wood R. Usefulness of total lymphocyte count in monitoring highly active antiretroviral therapy in resourcelimited settings. AIDS 2003;17:541-5.

15. Jacobson MA, Liu L, Khayam-Bashi H, Deeks SG, Hecht FM, Kahn J. Absolute or total lymphocyte count as a marker for the CD4 T lymphocyte criterion for initiating antiretroviral therapy. Aids 2003;17:917-9.

16. Kumarasamy N, Mahajan AP, Flanigan TP, Hemalatha R, Mayer KH, Carpenter CC, et al. Total lymphocyte count (TLC) is a useful tool for the timing of opportunistic infection prophylaxis in India and other resource-constrained countries. J Acquir Immune Defic Syndr 2002;31:378-83.

17. Daka D, Loha E. Relationship between total lymphocyte count (TLC) and CD4 count among peoples living with HIV, Southern Ethiopia: A retrospective evaluation. AIDS Res Ther 2008;5:26.

Cite this article as: Karanth SS, Rau NR, Gupta A, Kamath A, Shanbhogue V, Pruthvi BC. Utility of total lymphocyte count as a surrogate for absolute CD4 count in the adult Indian HIV population: A prospective study. Avicenna $\mathrm{J}$ Med 2014;4:1-4.

Source of Support: Nil, Conflict of Interest: None declared. 